\title{
EXAMINING THE REDUNDANCY EFFECT IN A MULTIMEDIA PRESENTATION ON RETENTION OF FRENCH VOCABULARY
}

\author{
Norehan Zulkiply ${ }^{1}$ \\ Nur Assyifaa Abdul Rahman ${ }^{2}$ \\ Faculty of Cognitive Sciences and Human Development \\ Universiti Malaysia Sarawak \\ ${ }^{1}$ znorehan@fcs.unimas.my \\ 2syifaa_penawar@yahoo.com
}

\begin{abstract}
The present study examined the effect of redundancy in the multimedia presentation on retention of French vocabulary. In the experiment, 40 undergraduate students who had been identified as having a low level of knowledge of the French language (determined through a prior-conducted pre-test) were asked to learn a series of French words using either one of two types of multimedia presentation: AN (animation and narration) or ANT (animation, narration and onscreen text). Results of an independent t-test performed on the post-test scores showed that both the AN and ANT groups performed significantly better in the posttest than in the pre-test. Nevertheless, the ANT group showed a higher increase in retention performance, indicating that the additional multimedia elements used in the ANT presentation had significantly improved the retention of French vocabulary. This result was consistent with the information delivery hypothesis but was not in accordance with the redundancy principle. The present finding could provide insights to learners and educators of alternative methods of learning and teaching foreign languages (such as French) which can enhance memory retention.
\end{abstract}

Keywords: Redundancy effect, multimedia presentation, visual channel, auditory channel, memory retention

\section{Introduction}

The use of multimedia presentations in language learning has become the interest of many researchers lately. A number of studies have been conducted to analyse the efficacy of a multimedia presentation as a learning tool that could help enhance the learning of a particular language (Borras \& Lafayette, 1994; Kim \& Gilman, 2008; Mayer, 2005; Plass \& Jones, 2005). Generally, in the traditional way of learning a language, students are presented only words and their associated meanings in a 
text-only format (Kim \& Gilman, 2008). However, with the development of technology, in particular the visualisation technologies and the powerful computer graphics, instructors have the ability to supplement the verbal modes of instruction with pictorial modes of instruction via an approach referred to as the multimedia presentation approach (Mayer, 2005).

For instance, in a study by Kim and Gilman (2008) which investigated the use of multimedia components such as visual text, spoken text and graphics to increase English vocabulary learning for middle school students in South Korea, it was found that adding graphics to the spoken and visual texts enhanced the learners' English vocabulary learning. It is argued that the graphics allowed the students to visualise the definition in a more meaningful way (Kim \& Gillman, 2008), thus making learning more effective.

The use of multimedia presentations has also been implemented more recently in the learning of foreign languages (i.e., Samur 2012). Samur (2012) used two types of multimedia presentation to investigate the learning of Turkish vocabulary among a group of students who had nil to low levels of knowledge about the Turkish language. The first type of multimedia presentation consisted of two elements - animation and narration (AN), whereas the second type consisted of three elements - animation, narration and on-screen text. Samur (2012) found that the students' retention of Turkish vocabulary was better when they were exposed to the ANT presentation rather than to the AN presentation. Consistent with the information delivery hypothesis, it is argued that those in the ANT group may have learned more of the French vocabulary because the words were exposed to them in multiple ways (involving three components of multimedia elements rather than only two multimedia elements, as in the AN presentation). The information delivery hypothesis states that when the same information is presented by more means than fewer means, it will facilitate better learning and retention (Mayer, Heiser \& Lonn, 2001). Nevertheless, Samur's (2012) findings were inconsistent with the redundancy principle which predicts that learning would be impaired if the elements in the presentation were redundant (Kalyuga, Chandler \& Sweller, 1999; Mayer et al., 2001). Redundancy occurs when the same information is presented in multiple forms or is unnecessarily elaborated (Sweller, 2005). In particular, adding on-screen text that duplicates words that are already spoken in the narration (as in the ANT) should have resulted in poorer learning.

The Ministry of Higher Education encourages Malaysian universities to provide foreign language courses for their students (Zubairi \& Sarudin, 2009). The benefit of studying a foreign language allows the students to become more confident in the international culture and should provide additional opportunities such as being able to access foreign technology, constructive engagement with foreign societies, politics, global trading and education. The work of Samur (2012) has inspired researchers to explore further the use of multimedia presentations in enhancing the learning of other foreign languages such as French, Arabic and Mandarin, which students usually take as one of their generic university courses. In learning a foreign language, learning the vocabulary words is crucial and it has been argued that "vocabulary learning is considered to be the basic step toward mastering a foreign language" (Huang \& Chen, 2011, p. 62). Thus, the present study 
aimed to examine the effect of redundancy in the multimedia presentation on the retention of French vocabulary. Using similar methodology to that used by Samur (2012), the study showed that students achieved a better retention of French vocabulary when they were exposed to the ANT condition, rather than the AN condition, thus allowing for further examination of the efficacy of redundancy in a multimedia presentation for foreign language learning.

\section{Methodology}

\section{Participants and design}

The participants were 40 undergraduate students ( 26 female, 14 male) from a local public university. In order to examine whether or not the findings obtained by Samur (2012) in his study examining the effect of redundancy in multimedia presentation on the retention of Turkish vocabulary can be generalised to French vocabulary, it is crucial for the present study to follow the same methodology used by Samur (2012), and that includes the design of the experiment, the development of experimental materials (except the present study used French vocabulary) and the procedures of experiment. In particular, a quasi-experimental research design (see Table 1) involving the following three stages was implemented: (i) pre-test, (ii) treatment (i.e., multimedia presentations), and (iii) post-test.

Table 1.

Research design

\begin{tabular}{cccc}
\hline Groups & Before Treatment & During Treatment & $\begin{array}{c}\text { After } \\
\text { Treatment }\end{array}$ \\
\hline Control & Pre-test & Animation + narration & Post-test \\
Treatment & Pre-test & Animation + narration + text & Post-test \\
\hline
\end{tabular}

\section{Materials and Instruments}

Following Samur (2012), for data collection purposes, a paper and pencil type of multiple-choice test was utilised for both AN \& ANT groups. The same 10 items based on some basic action verbs in the French language were included in the pre-test and post-test (see Appendix). A paper and pencil test is a preferred type of data collection procedure for this kind of study because it is easy to administer, and the use of multiple-choice is suitable to assess ability to recall a list of simple facts such as basic action verbs used in the present study. Additionally, an open-ended question was added to the post-test, which asked the participants' opinions about the multimedia presentation they received and their thoughts about their learning experiences with the multimedia presentation (see Appendix). The test was developed by taking into account the advice of a French language expert and was pilot-tested by a sample of undergraduate students in order to improve the item format and clarity before they were presented to the participants in the actual experiment. Figure 1 shows selected frames from ANT which includes animation 
along with concurrent narration and on-screen text, whereas Figure 2 shows selected frames from AN which include animation and concurrent narration.
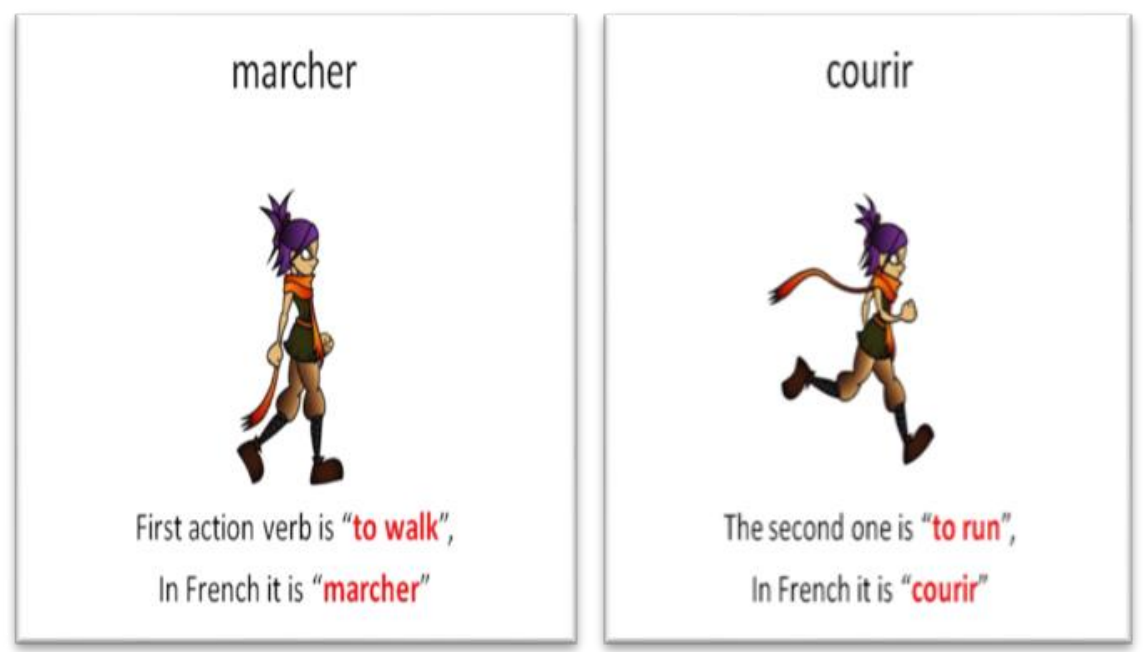

Figure 1. Selected frames from the multimedia presentation of the ANT group.
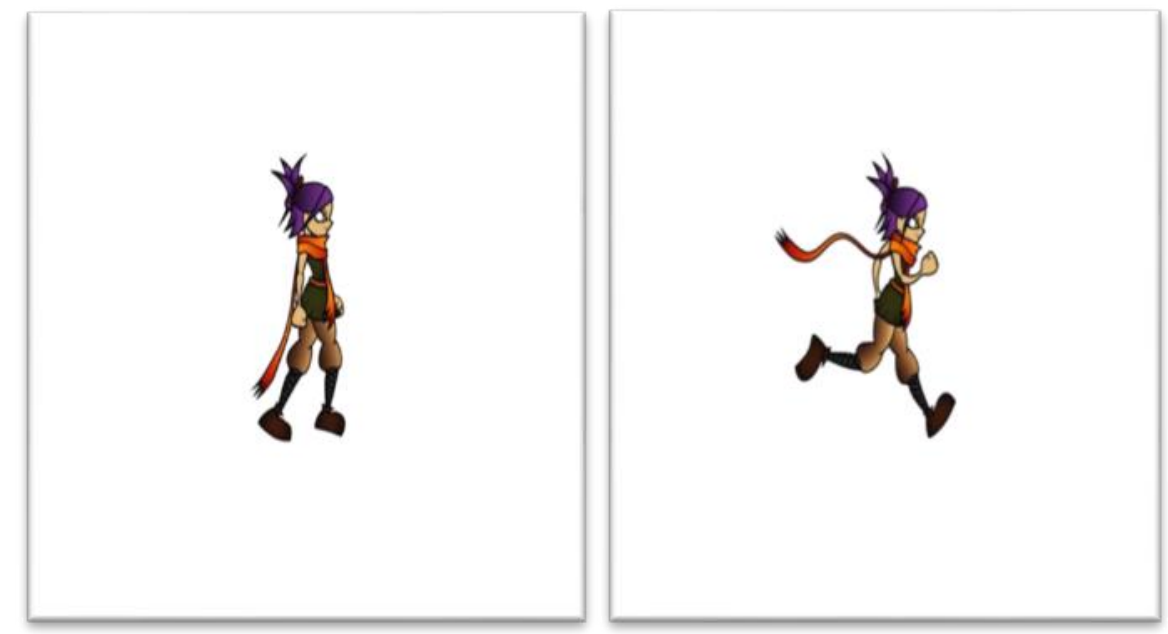

Figure 2. Selected frames from the multimedia presentation of the AN group.

\section{Procedure}

A standard procedure of obtaining participants' consent and instructing them in the nature of the experiment was conducted before the pre-test began. During the individually administered pre-tests, each participant was given a set of multiple-choice tests with the intention of selecting only the most qualified students. This was part of the screening process where the participants who scored three or below were selected for the next stage to ensure that participants had a low level of knowledge in French vocabulary. Participants were informed in advance that they 
would be notified later by the researcher as to whether or not they were selected to participate in the next stage (multimedia presentation). As it happened, all 40 participants scored three or below, (which was the requirement that has been set) and thus proceeded to the next stage.

Participants were then randomly assigned to either the control group or the treatment group. During treatment, participants were given two and a half minutes of a multimedia presentation in which the control group was assigned to the AN multimedia presentation while the treatment group received the ANT multimedia presentation. Participants were told to learn 10 French action verbs during the multimedia presentation.

At post-test, participants were given the same set of multiple-choice tests as had been administered during the pre-test, probing their knowledge of the 10 action verbs that they had learned during the multimedia presentation. Finally, participants were debriefed about the experiment before they left the room.

\section{Results and Discussion}

First, to examine whether or not there is any significant difference in terms of memory retention of French vocabulary between the AN group and the ANT group in pre-test scores, as well as in their post-test scores, independent sample t-tests were performed. The result shows that there is no significant difference in the pretest score between the AN group and the ANT group, $\mathrm{t}(38)=1.65, p=.67$, indicating that the participants' levels of prior knowledge of French vocabulary was almost equal. In particular, all 40 participants obtained scores of 3 and below showing that they have very little to no knowledge of French vocabulary. When interviewed further, those who managed to obtain the correct answers (scoring 1, 2 or 3) reported that their score was mainly due to correct guessing and not actual knowledge of those French action verbs. Interestingly, the post-test scores of the two groups showed that participants in the ANT group performed significantly better than those in the AN group, $\mathrm{t}(38)=4.73, p=.035$. Table 2 shows the means and standard deviations for the pre-test and post-test in the two multimedia presentation conditions (AN vs. ANT).

Table 2

Means and standard deviations of pre-test and post-test for each condition

\begin{tabular}{lcccc}
\hline & \multicolumn{3}{c}{ AN } & \multicolumn{2}{c}{ ANT } \\
\cline { 2 - 5 } & $\mathrm{M}$ & SD & M & SD \\
\hline Pre-test score & 2.20 & 0.76 & 1.80 & 0.76 \\
Post-test score & 3.80 & 1.61 & 6.95 & 2.50 \\
\hline
\end{tabular}

From Table 2, it can be seen that at post-test, participants who received the ANT presentation had a better retention of the French vocabulary ( $M=6.95, S D 2.50)$ than those who received the AN presentation, which is without the on-screen text $(M=3.80, S D 1.61)$. This pattern of statistics is consistent with the results observed by Samur (2012). Thus, further analysis using a paired-samples t-test was conducted in order to examine whether the difference is significant when it is compared with 
the pre-test retention test results for each group. In the ANT group, the post-test score of the retention test were significantly higher than the pre-test score, $t(19)=-$ $9.07, p=.000$, and this finding parallels Samur's (2012) results. The present study also found a significant difference between the post-test and the pre-test score on the retention test in the AN group, $t(19)=-3.71, p=.001$, and interestingly, this finding was not observed by Samur (2012). Nevertheless, the pattern of means for both the pre-test and post-test in Samur (2012) is consistent with the present study; that is, performance in the post-test is slightly better than the pre-test.

Although different, both types of multimedia presentation (AN \& ANT) seem to show an increased retention of French vocabulary. Nevertheless, the higher posttest score of the retention test in the ANT condition ( $M=6.95$ compared to the AN $(M=3.80)$ indicates that ANT is likely to be a more powerful approach in facilitating the retention of French vocabulary. Participants who received the ANT presentation (Animation plus Narration and Text) outperformed those who received AN (Animation plus Narration). Referring to the group means (see Table 2), the ANT group has shown a remarkable difference in mean from 1.80 (pre-test) to 8 (posttest), indicating an improvement in the participants' retention of French vocabulary. This magnitude of the increase observed in the ANT group is relatively high when compared to the smaller increase (1.6 up to 3.8 ) in the AN group, considering that this is their first time they had studied the French language.

The present finding is consistent with the information delivery hypothesis which states that when the same information is presented by more ways, it facilitates better learning and retention (Mayer et al., 2001). In the present study, the French vocabulary words are presented to the participants in more ways through ANT and this has likely contributed to the better retention of French vocabulary by this group. In particular, the addition of on-screen text to a multimedia presentation with animation and narration (as in the ANT) may have helped the learning of the new vocabulary of a previously unfamiliar foreign language (i.e., French).The present finding concurs with Samur's (2012) findings involving Turkish vocabulary as well as Kim and Gilman's (2008) study using English vocabulary. Both Samur (2012) and Kim and Gilman (2008) found that instruction based on visual text and graphics along with added spoken text helped enhance students' learning and retention of the newly learned vocabulary. Incorporating text and pictures in vocabulary learning has resulted in a better retention of vocabulary (Paivio, Clark, \& Lambert, 1988; Plass \& Jones, 2005).

Further analysis conducted on the participants' answers to the open-ended question showed that the majority of the participants who received the ANT thought that the ANT presentation was interesting and that the animation together with the text and narration had made the learning of the new vocabulary words enjoyable. On the other hand, most of the participants in the AN group found it difficult to appreciate the new vocabulary words they were learning - some reported that the words sounded similar, while some reported that the writing and pronunciation of French words is different. Participants' responses seem to be in accordance with points highlighted by Grace (1998), that is, the retention of the participants who cannot see the meaning of the words in their native language (like those in the AN group in the present study) is nearly four times lower than those who can see the 
meaning of the words in their native language (like those in the ANT group in the present study). Thus the latter are likely to make correct inferences of the meaning of the words in the future. Further, it is argued that participants who can see the translations can verify the correctness of the meaning of the words and thus ensure the correct meaning of the words is committed to memory.

The present finding however does not comply with the redundancy principle (Kalyuga et al., 1999; Mayer et al., 2001), the limited capacity theory (Baddeley, 1992) and dual channel theory (Clark \& Paivio, 1991). The redundancy principle suggests that learning should be impaired if the elements in the presentation are redundant (Kalyuga et al., 1999; Mayer et al., 2001). Having auditory textual explanations duplicated in a visual form significantly inhibits learning due to an increase in cognitive load (Kalyuga et al., 1999). Adding the on-screen text that contained the same words as in the narration impaired the narrated animation of the scientific explanation (Mayer et al., 2001). It is argued that "the on-screen text may have created a cognitive load either by competing with the animation for cognitive resources in the visual channel or by demanding resources in the auditory channel to reconcile the auditory and text-presented versions" (Mayer et al., 2001, p. 192). According to the limited capacity theory, humans have a limited information processing capacity; thus an appropriate distribution of cognitive resources is needed in order for one to conduct efficient learning, particularly for novices in any learning domain (Baddeley, 1992; Kalyuga, Chandler, \& Sweller, 2004). Further, according to the dual channel theory, cognition involves the activity of two distinct subsystems - the verbal system specialised for dealing directly with language - and a nonverbal (imagery) system, specialised for dealing with non-linguistic objects and events (Clark \& Paivio, 1991). In the present experiment, redundancy may exist in the ANT presentation when the on-screen text is added to the presentation which duplicates the narrated word - this could have caused a competition at the verbal channel of information processing resources which are also processing the narrated text. In the AN presentation, the picture animation is processed at the visual channel of the working memory whereas the narrated text is processed separately at the verbal channel; thus, technically there is no competition between elements and therefore redundancy does not exist. Nevertheless, such explanations fail to support the findings of the present study which showed that ANT (as compared relatively to AN) greatly enhanced the retention of the French vocabulary. According to Moreno and Mayer (2002), the negative effect of verbal redundancy may disappear and the verbal redundancy may even foster leaning if it is made sequential. Such explanation further supports the present findings - in the present experiment, the on-screen text appears first (together with the animation of the verb), and the narrated text follows immediately after. It seems that the redundant verbal materials do not have a negative effect on learning via the ANT multimedia presentation (where on-screen and narrated text existed), and in fact, the superior learning and retention of the French vocabulary is achieved even with the addition of the on-screen text (as compared to the performance in the AN). 


\section{Conclusion}

In the present study, the effect of redundancy in a multimedia presentation on the retention of French vocabulary was examined using two types of multimedia presentation, AN \& ANT. The present findings show that both the AN and ANT multimedia presentations helped in the retention of French vocabulary; however, a remarkable increase in performance was seen in those who received ANT. The finding from the present study shows that the ANT presentation greatly helped students to learn new vocabulary of an unfamiliar language. In particular, the redundancy between the narrated text and on-screen text existing in the ANT condition did not impair learning of the new vocabulary. The findings are supported by the information delivery hypothesis which affirms that presenting the same information using various paths and means facilitates more learning. The present finding gives a new insight to learners and educators of an alternative means of learning and teaching a foreign language (such as French) that can improve and enhance memory retention of the learned vocabulary. The use of the ANT presentation seems to be highly practical not only for students, but educators (i.e., language teacher) as well since by using it, teachers may improve their teaching practices, particularly in foreign language learning. In future research, it would be interesting to examine the effect of redundancy in a multimedia presentation on the retention of foreign vocabulary (such as French) among male and female learners as well as those with different learning styles and preferences. A recent study shows that females learn better with animations whereas males learn better with nonanimated pictures (Cowards, Crooks, Flores \& Dao, 2012), thus implying the possibility that gender differences may also exist in foreign language learning using different elements of multimedia presentation. The multimedia presentation incorporates multiple representation of content such as text, audio and interacting images. Hence, a question for future research is whether the use of multimedia presentation would be able to cater more effectively to the different learning styles and modal preferences of diverse learners.

\section{References}

Baddeley, A. (1992). Working memory. Science, 255, 556-559.

Borras, I., \& Lafayette, R. C. (1994). Effects of multimedia courseware subtitling on the speaking performance of college students of French. The Modern Language Journal, 78, 61-75.

Clark, J. M., \& Paivio, A. (1991). Dual coding theory and education. Educational Psychology Review, 3, 149-210.

Cowards, F. L.; Crooks, S. M.; Flores, R., \& Dao, D. (2012). Examining the effect of gender and presentation mode on learning from a multimedia presentation. Multidisciplinary Journal of Gender Studies, 1, 4869. doi: 10.4471/generos.2012.03

Grace, C. (1998). Retention of word meanings inferred from context and sentencelevel translations: implications for the design of beginning-level CALL software. The Modern Language Journal, 82, 533-544. 
Huang, C. H., \& Chen, P.C. (2011). Enhancing EFL learners' vocabulary retention by Integrating new words into writing activities. Retrieved from http://140.127.82.166/retrieve/11975/62.pdf

Kalyuga, S., Chandler, P., \& Sweller, J. (1999). Managing split-attention and redundancy in multimedia instruction. Applied Cognitive Psychology, 13, 351-371.

Kalyuga, S., Chandler, P., \& Sweller, J. (2004). When redundant on-screen text in multimedia technical instruction can interfere with learning. Human Factors: The Journal of the Human Factors and Ergonomics Society, 46, 567-581. doi:10.1518/hfes.46.3.567.50405

Kim, D., \& Gilman, D. A. (2008). Effects of text, audio, and graphic aids in multimedia instruction for vocabulary learning. Educational Technology \& Society, 11, 114-126.

Mayer, R. E., Heiser, J., \& Lonn, S. (2001). Cognitive constraints on multimedia learning: When presenting more material results in less understanding. Journal of Educational Psychology, 93, 187-198. doi: 10.1037//00220663.93.1.187

Mayer, R. E. (2005). Introduction to multimedia learning. In R. E. Mayer (Ed.), The Cambridge handbook of multimedia learning, (pp. 1-15). New York: Cambridge University Press.

Moreno, R., \& Mayer, R. E. (2002). Verbal redundancy in multimedia learning: When reading helps listening. Journal of Educational Psychology, 94, 156-163. Doi: 10.1037//0022-0663.94.1.156

Paivio, A., Clark, J. M., \& Lambert, W. E. (1988). Bilingual dual-coding theory and semantic repetition effects on recall. Journal of Experimental Psychology: Learning, Memory, and Cognition, 14, 163-172.

Plass, J. L., \& Jones, L. C. (2005). Multimedia learning in second language acquisition. In R. Mayer (Ed.), The Cambridge handbook of multimedia learning (pp. 467488). New York: Cambridge University Press.

Samur, Y. (2012). Redundancy effect on retention of vocabulary words using multimedia presentation. British Journal of Educational Technology, 43, 166-170. doi:10.1111/j.1467-8535.2012.01320.x

Sweller, J. (2005). The redundancy principle in multimedia learning. In R. E. Mayer (Ed.), the Cambridge handbook of multimedia learning (pp. 159-167). New York: Cambridge University Press.

Zubairi, A. M., \& Sarudin, I. H. (2009). Motivation to learn a foreign language in Malaysia. GEMA Online Journal of Language Studies, 9, 73-87. 


\section{Appendix: List of Items included in the Pre-test and Post Test.}

1. What does "to walk" mean in French?
A. Parler
B. Marcher
C. Manger
D. Peindre

2. What does "to run" mean in French?
A. Courir
B. Jouer
C. Dormir
D. Ecrire

3. What does "to eat" mean in French?
A. Marcher
B. Lire
C. Jouer
D. Manger

4. What does "to read" mean in French?
A. Rire
B. Ecrire
C. Lire
D. Peindre

5. What does "to write" mean in French?
A. Marcher
B. Lire
C. Rire
D. Ecrire

6. What does "to laugh" mean in French?
A. Courir
B. Dormir
C. Rire
D. Jouer

7. What does "to play" mean in French?
A. Manger
B. Jouer
C. Parler
D. Dormir

8. What does "to paint" mean in French?
A. Peindre
B. Ecrire
C. Parler
D. Lire 
9. What does "to talk" mean in French?
A. Courir
B. Peindre
C. Parler
D. Marcher

10. What does "to sleep" mean in French?
A. Manger
B. Rire
C. Dormir
D. Courir

The following is an additional item included in the post-test.

How do you feel about the presentation and what do you think about your learning? 